\title{
Desenvolvimento Regional e Análise de Redes Sociais: um estudo do Arranjo Produtivo Local (APL) caprinovinocultura em Pernambuco-Brasil 1
}

Desarrollo Regional y Análisis de Redes Sociales: Arreglo Productivo Local de creación de caprino y ovino en Pernambuco-Brasil

\author{
Marcos Aurélio Dornelas ${ }^{2}$ \\ José Geraldo Pimentel Neto ${ }^{3}$ \\ Marcia Maria Pereira Lira ${ }^{4}$ \\ ITEP, Brasil
}

\section{Resumo}

Os fluxos de recursos em um arranjo econômico dependem do ambiente social em que as organizações estão inseridas. A caprinovinocultura é economia secundária na maioria dos municípios pernambucanos. Entretanto, se reconhecia a existência de um Arranjo Produtivo Local (APL) caprinovino no Estado. Tal arranjo, composto por oito cidades, foi a base para este trabalho que é parte de um diagnóstico realizado no ano de 2011 sobre a governança do APL. Foram aplicados questionários as organizações envolvidas com a atividade econômica no sentido de analisar a estruturação socioinstitucional em termos de fluxos e influência. Observou-se que a união de criadores em torno de associações pode estar na base de uma governança local mais eficiente, permitindo maior acesso a crédito e a mercado. Esse ambiente favorável se observa em algumas das cidades aqui analisadas. Em outros municípios, a dificuldade de articulação entre as esferas públicas já é fator suficiente para que o APL não se desenvolva adequadamente. Logo, não há fator determinante para o sucesso de um APL; vários aspectos

\footnotetext{
${ }^{1}$ Este artigo está vinculado a um projeto do CNPq (Edital MCT/CNPq/ Ação Transversal I No. 039/2008) denominado: "Rede de Inovação para o Desenvolvimento Regional: Um instrumento para Fortalecimento do Arranjo Produtivo Local de Caprinovinocultura em Pernambuco".

${ }^{2}$ Doutor em Sociologia pela UFPE e Pesquisador do Instituto de Tecnologia de Pernambuco - ITEP. Email: madornelas@gmail.com

${ }^{3}$ Doutorando em Desenvolvimento urbano pela UFPE e Coordenador Técnico do Instituto de Tecnologia de Pernambuco - ITEP. E-mail: gerageo@gmail.com

${ }^{4}$ Mestre em Gestão e Política Ambiental pela UFPE e Superintendente de Inovação Tecnológica do ITEP. E-mail: marcialira.itep@gmail.com
} 
concorrem, desde a capacidade de organização dos criadores, a disponibilidade de financiamento, ou mesmo a ação governamental; certo é que esses fatores, geralmente articulados, são fundamentais para o sucesso do Arranjo.

Palavras chave: Redes sociais, APL, Caprinovinocultura, Pernambuco.

\section{Resumen}

Los flujos en un arreglo productivo dependen del entorno social en el que las organizaciones están insertadas.La creación de caprinos y ovinos es una economía secundaria en la mayoría de los municipios de Pernambuco. Sin embargo, se reconoce la existencia de un Arreglo Productivo Local (APL) de creación de caprinos y ovinos en Pernambuco. Ese arreglo productivo, compuesto por ocho ciudades fue la base para este trabajo. Se aplicaron cuestionarios a las organizaciones relacionadas con la actividad económica con el fin de analizar la estructura socioinstitucional en términos de flujos e influencia. Se observó que la unión de creadores en torno a las asociaciones puede ser la base para una gobernanza local más eficiente. Este contexto favorable se observa en algunas ciudades, en otros municipios, la dificultad de articulación es entre las esferas públicas, es factor suficiente para que el APL no se desarrolle adecuadamente. No se puede poner un factor decisivo para el éxito de un APL, varios aspectos se pueden enumerar, como la capacidad organizativa de los agricultores, la disponibilidad de financiamiento 0 la acción gubernamental, lo cierto es que estos factores articulados, son fundamentales para el éxito de la creación de caprinos y ovinos en arreglo local.

Palabra clave: Redes sociales, APL, Creación de caprinos y ovinos, Pernambuco.

\section{Abstract}

Knowledge flows in an economic arrangement depend on the social environment in which organizations are embedded. The caprinovinocultura is a secondary economy in most municipalities of Pernambuco. However, it is recognized the existence of a Local Productive Arrangement (APL) caprinovino in the state. This arrangement, composed of eight cities, was the basis for this work which is part of a survey conducted in 2011 on the governance of the network of APL. It was researched organizations involved in economic activity in order to analyze the socioinstitutional structure in terms of flows and influence. Was observed that the union of creators around associations can be the basis for local governance more efficient, allowing greater access to credit and markets. Thisenvironment is seen in some cities analyzed, as in the case of Sertânia and Serra Talhada. In other towns, difficulty of articulation between Public Sphere, particularly the Technical Assistance and the Departments of Agriculture and Livestock factor is sufficient for the APL does not develop properly. Unable to finally put a decisive factor for the success of a APL, several aspects can be listed, since the organizational capacity of goat breeder, availability of funding for the activity, or even government action. It is true that these factors, articulated, are fundamental to the success ofcaprinovinocultura in local arrangements.

Keywords: Social networks, APL, Caprinovinocultura, Pernambuco.

\section{Introdução}

Quando se admite que dentro das estruturas sociais em rede possa haver hierarquias e distribuição de poder desigual, esta se partindo de uma concepção distinta da popularizada que identifica 'rede' como um modelo de gestão horizontal em que os elos de uma cadeia qualquer partilham de modo igualitário recursos e 
poder. Ainda que se suponha que algo desse tipo possa existir, não é deste tipo de 'rede' enquanto forma de gestão que se está tratando neste trabalho. Para a perspectiva da Análise de Redes Sociais (ARS) o fato de existir o contato, por si só, já configura uma rede, ou seja, saber se os fluxos circulam de forma mais ou menos horizontal é uma questão de investigação. A ARS distingue-se, de outras análises, por privilegiar a relação e os fluxos entre nodos e não apenas os atributos desses nodos, assim parte-se da ideia de que a interação tem um papel importante na construção de conceitos, na formulação de perguntas e na análise das estruturas sociais.

Logo, o modo como os indivíduos vivem em sociedade depende em larga medida da maneira como eles estão ligados em conexões sociais.

Os laços de associação entre os homens são incessantemente feitos e desfeitos, para que então sejam refeitos, constituindo uma fluidez e uma pulsação que atam os indivíduos mesmo quanto não atingem a forma de verdadeiras organizações. (...) os indivíduos estão ligados uns aos outros pela influência mútua que exercem entre si pela determinação recíproca que exercem uns sobre os outros. (Simmel, 2005. P. 17)

Essas conexões, ou redes, são estruturas de sociabilidade de dois tipos, (1) as que interligam os indivíduos entre si, dando origem a vários tipos de redes de nível micro; e (2) as que ligam os indivíduos e as organizações sociais, gerando todo tipo de redes mesoestruturais ${ }^{5}$ (Degenne; Forse, 1999). Partindo-se deste princípio, o espaço social é formado por indivíduos e organizações interagindo entre si, em um espaço-temporal determinado.

A qualidade e a quantidade de cruzamentos presentes em uma rede dependem de vários fatores; entre os principais pode se elencar:

(1) tempo de contato: o tempo é importante, mas nunca pode ser entendido por si só, visto que ter contato há longo tempo não significa necessariamente ter um contato intenso;

(2) frequência de contato: a frequência geralmente responde pela possibilidade pelo aprofundamento de um contato;

(3) proximidade relacional: A proximidade geográfica, mesmo na era da chamada compressão espaço-tempo, pode ser importante para entender a intensidade de contatos, principalmente se tratando de empresas, onde o aumento da distância pode significar maiores custos. Em termos formais, para a análise de redes sociais,

\footnotetext{
${ }^{5}$ A divisão é meramente lógica, já que as organizações são compostas de indivíduos que em última instancia, por meio da formação de grupos, são à base da sociabilidade em rede.
} 
e com base na teoria de grafos, a proximidade é medida com base na distância entre nodos a partir de seus laços adjacentes.

(4) Fluxo de recursos: recursos, entendido de modo amplo, diz respeito ao que circula entre partes em interação, desde recursos emocionais entre indivíduos, até recurso financeiro entre empresas e Estados.

O resultado da intersecção desses fatores diferenciadores das relações responde pela capacidade de cada nodo em mobilizar recursos desejados. Seguindo este argumento, a quantidade de recursos sociais que um nodo mobiliza não tem relação apenas com sua capacidade imediata de organizar estratégias, mas repousa também nos processos interativos construídos, destruídos ou reconstruídos em rede. (Wellman, 1988). Neste sentido, as redes de sociabilidade influenciam as oportunidades que os indivíduos e entidades sociais têm em seu mundo social. Tal influência ocorre porque alguns recursos simplesmente não estão disponíveis em determinadas redes, segundo, as redes funcionam como campos que interferem no próprio comportamento dos indivíduos no grupo e nas escolhas por eles realizadas. Por fim, a capacidade de adaptação por parte dos indivíduos é fundamental para compreender como estão distribuídos os recursos numa rede social. (Scott, 2000)

\section{Metodologia de Análise de Redes Sociais (ARS)}

A análise de redes sociais tem três fundamentos metodológicos, a estatística, a análise de clusters e a análise de grafos, todas com alto grau de formalização de indicadores. Isso implica dizer que suas análises partem de argumentos matemáticos para derivar afirmações teóricas. Neste trabalho limitaremos o escopo de análise aos grafos e as derivações de análise por meio de sociogramas.

De modo simples, grafo é um conjunto de pontos, convencionalmente chamados vértices ou nodos, conectados por linhas chamadas de arcos ou arestas. Na ARS os grafos são utilizados como modelo de representação das relações, permitindo rápida observação de dados, facilitando algumas formas de análise. A análise de grafos permite várias formas de compreender as redes sociais.

\section{Medidas de centralidade e densidade}

Combinaremos a análise de grafos com as medidas de centralidade que pretendem indicar a importância de cada nodo na estrutura da rede, são várias as medidas de centralidade, as que serão trabalhadas aqui são: (a) grau de Centralidade (degree 
centrality). Refere-se a quantidade absoluta de contatos elencados por um nodo. Indicando a atividade do nodo na rede e sua capacidade de diversificação de parceiros. (Mccarty, 2002) (b) grau de intermediação (betweenness centrality). refere-se a quantidade de vezes que determinado nodo é utilizado por outro como caminho para alcançar um terceiro. Indica potencialidade de controle de fluxo de informação e poder de funcionar como ponte entre nodos não adjacentes. (Hanneman \& Riddle, 2005)

Diferente da centralidade, o foco da análise de densidade está não no indivíduo, e sim na estrutura. A densidade busca identificar o quanto uma rede está interligada facilitando o fluxo entre os elos de modo mais igualitário. (Duarte, 2008). Em termos práticos a densidade responde pela capacidade da rede como um todo de funcionar integrada, o que pode ser muito bom para os atores, por um lado, na medida em que com fluxo facilitado a segurança aumenta. Entretanto, por outro lado, quando se está numa rede muito densa a renovação de informação fica prejudicada. A densidade calcula-se por meio da proporção entre a quantidade de elos existentes pelo total de elos possíveis na estrutura. A densidade varia de 0 a 1 . $O$ ' $O$ ' indica que não há qualquer contato entre os elos, e o ' 1 ' por outro lado, contato direto e total entre todos os elos de uma rede. (Mc Carty, 2002)

\section{Desenho da pesquisa: o APL segundo o MDIC}

No ano de 2008, o Ministério do Desenvolvimento, Indústria e Comércio Exterior (MDIC) definiu que o Arranjo Produtivos Local (APL) da Caprinovinocultura em Pernambuco, era composto por oito municípios. Os municípios são: Arcoverde, Sertânia, Afogados da Ingazeira, Tuparetama, Carnaíba, Salgueiro, Serra Talhada e Floresta. O levantamento da rede sócio-institucional a partir destas cidades teve dois momentos. Uma primeira viagem de reconhecimento das entidades iniciais da pesquisa e o segundo momento no qual foram realizados os questionários com base no método bola-de-neve.

Há basicamente duas formas de se trabalhar amostragem em ARS: tendo acesso a todos os membros de uma rede, é possível empregar o método conhecido como whole network study, neste tipo de estudo se verifica a inter-relação entre todos os membros de um grupo. Por exemplo: um grupo de funcionários em uma empresa. Neste caso, há duas maneiras convenientes de montar os dados; a que despende mais tempo e recurso é por meio da observação direta das relações, outra é por meio de entrevistas em que cada um fala da relação que mantém com os demais membros do grupo. 
Mas nem sempre se conhece os limites da rede, tornando-se necessário empregar métodos de coleta como o bola-de-neve, que será o empregado aqui. Isso porque se conhece os municípios que serão pesquisados, mas não se sabe de antemão as organizações a serem entrevistadas. Neste caso se identifica atores potencialmente importantes e a partir deles se conhece novos nodos. Uma limitação evidente é que não há garantias sobre o reconhecimento de todos os nodos importantes, já que a rede é a princípio egocentrada, e, portanto, dependente da indicação de parceiros. Neste tipo de método, o foco é compreender como os parceiros se influenciam mutuamente.

A amostra é tida como inicial porque apesar de haver um ponto de partida, a metodologia empregada não define um ponto final. É a partir da citação de parceiros por parte dos atores que se conhece as próximas entidades a entrevistar. Neste trabalho, ir até a segunda vizinhança dos pontos iniciais foi suficiente para conhecer a rede de parcerias, visto que a partir desde momento os parceiros já apresentam expressiva repetição.

Para a indicação das entidades iniciais, não foi possível levar em conta uma divisão proporcional entre as cidades, o critério foi a localização, por meio da pesquisa exploratória, de entidades representativas localmente, privilegiando Secretarias de Agricultura, associações de criadores e órgãos de controle e apoio as atividades da caprinovinocultura nos oito municípios, geralmente o Instituto Agronômico de Pernambuco-IPA e a Agência de Defesa e Fiscalização Agropecuária de Pernambuco-ADAGRO. A correção de um possível viés de pesquisa ocasionado pela escolha das entidades iniciais foi feita nas visitas posteriores às cidades.

Foram dois os instrumentos de coleta de dados primários, o primeiro quantitativo e o segundo qualitativo; (1) o questionário divido em duas partes: (a) caracterização da entidade entrevistada; (b) e indicação da rede de parceiros; e (2) o registro escrito das especificidades das relações entre parceiros.

O questionário na parte da caracterização procura conhecer a instituição em sua estrutura, quantidade de participantes, tempo de existência, campo de atuação principal etc. Na parte de redes, o foco do instrumento está na reconstrução das relações estabelecidas pelas entidades que apoiam a cadeia da caprinovinocultura. Por meio das respostas das entidades foi possível dar conta da verificação do raio de ação delas, sua capacidade de diversificação de parcerias, a quantidade e a qualidade das parcerias locais e regionais, a capacidade de cooperação entre as entidades por meio da verificação de reciprocidades.

A qualificação da relação dos parceiros é feito por meio das seis questões a seguir: 
- Como se deu o primeiro contato com a entidade?

- Qual o tipo de contato que mantêm com as entidades citadas?

- Qual a forma de contato mais frequente com as

- Quais as atividades desenvolvidas em parceria?

- Qual a duração dos trabalhos realizados?

- Como avalia os trabalhos realizados em parceria?

Os dados levantados por meio do questionário são levados para o SPSS6, onde são tratados e transferidos para o UCINET7 sob a forma de matrizes quadradas. 0 UCINET dispõe de ferramentas estatísticas e gráficas de análise; neste trabalho utilizaremos o aplicativo Netdraw, que é parte do pacote UCINET, para gerar gráficos de redes, essas imagens são grafos que representam as relações entre as entidades pesquisadas. As ferramentas gráficas utilizadas serão: as análises de centralidade, de reciprocidade, de espacialização, de formação de grupos e análise de centralização.

\section{Análise das redes das cidades}

Os fluxos de conhecimento em um arranjo econômico dependem do ambiente social em que as entidades estão trabalhando, fatores políticos e econômicos, entre outros, importam na sobrevivência e crescimento de organizações. Tratando especificamente da caprinovinocultura, na medida em que incentivos governamentais garantem a compra de produção, por exemplo, há um incremento de confiança por parte dos produtores. O mesmo acontece em relação aos fatores econômicos: estar numa atividade rentável e com facilidade de crédito a juros razoáveis torna a empresa da criação e produção caprinovina mais atrativa aos criadores e produtores. Esse ambiente favorável se observa em algumas das cidades aqui analisadas, como é o caso de Sertânia e Serra Talhada. Em outras, a dificuldade de articulação entre as esferas pública, particularmente as unidades do IPA, e Secretarias já é fator suficiente para que todo o arranjo não funcione a contento. Não é possível colocar se o fator determinante para o sucesso de um arranjo está na capacidade de organização dos criadores, na capacidade de financiamento presente nas cidades, ou mesmo na ação governamental, certo é que esses fatores, geralmente articulados, são fundamentais para o sucesso da caprinovinocultura nas redes locais.

\footnotetext{
${ }^{6}$ Statistical Package for the Social Sciences. Software de análise estatística.

7 Pacote de softwares para a análise de dados reticulares.
} 
Sociograma 1 - Rede sócio-institucional da Caprinovinocultura por Região de Desenvolvimento, sem pendentes

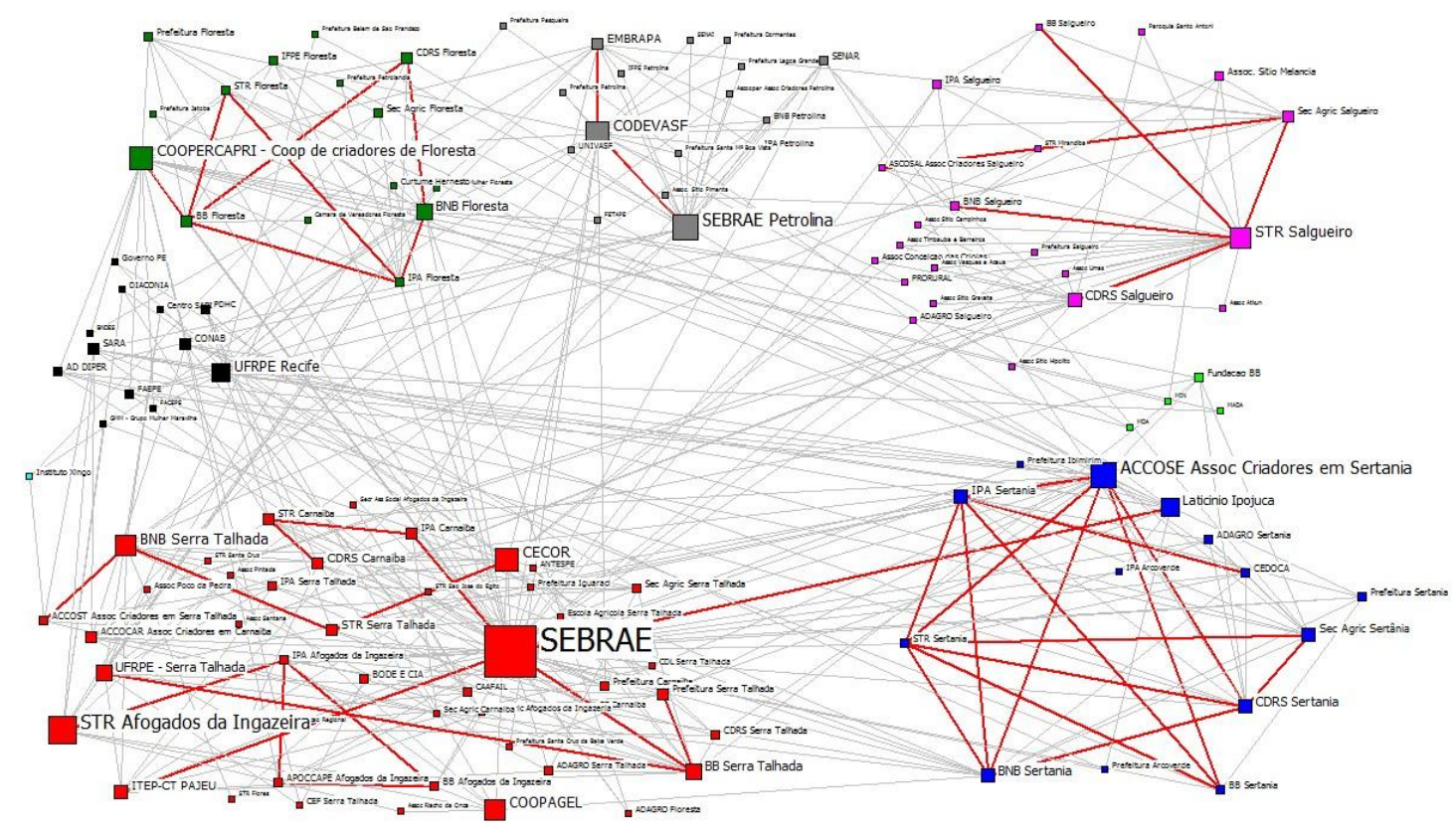

A análise com base nas Regiões de Desenvolvimento-RD pretende indicar a integração regional e a presença de entidades nestes espaços. A imagem permite verificar que a RD onde há maior densidade institucional é a região do Pajeú, cujos nodos estão no campo esquerdo do sociograma, em vermelho. Ao lado desta, no sociograma, a RD metropolitana, talvez por ter a capital Recife, aparece com nodos bem relacionados com praticamente todas as outras RDs, principalmente com a do Pajeú, apesar da distância geográfica. A RD com menos conexões externas é a do Sertão Central, cuja cidade mais importante é Salgueiro, na imagem, no canto esquerdo, acima. A relação entre os nodos das demais RDs é equitativa, já que em cada uma delas há pelo menos uma cidade bem representada e com ligações internas em número razoável.

Apenas uma reciprocidade - as linhas vermelhas representam os laços recíprocos extrapola o âmbito das RD, diz respeito à conexão entre o SEBRAE e o Laticínio Ipojuca, a primeira, na RD Pajeú, a segunda na Moxotó. Este fato leva a crer que as relações mais intensas são territorialmente ancoradas nos espaços das Regiões de Desenvolvimento. Entretanto, mesmo dentro do espaço das RDs ou seja, entre as cidades, há apenas um laço recíproco entre entidades, novamente o SEBRAE, desta vez com o IPA de Carnaíba. Essa característica provavelmente diz respeito, por um lado, ao tipo de mercado da caprinovinocultura, como os produtos e a maioria dos produtores e empresas não contam com uma malha de distribuição ampla, os laços 
mais importantes estão em geralmente na mesma cidade. Para este fato concorre também, de forma complementar, a dependência da atividade em relação às entidades governamentais, conforme será discutido mais a frente.

\section{Medidas de rede estruturais e relacionais}

Neste trabalho, buscou-se identificar os canais de articulação das empresas, associações de criadores, entidades governamentais e demais entidades ligadas à atividade da caprinovinocultura, esta identificação visa compreender a rede de dois modos, de um lado importa conhecer a estrutura em si, fatores como a conectividade e densidade. $\mathrm{E}$ de outro lado, tem-se as análises de centralidade que permitiram compreender os fluxos de recursos nas redes e fatores como concentração, poder etc.

A primeira das análises trabalhadas é o grau de centralidade. A visualização da rede com todos os laços implica alguma dificuldade de visualização devido a grande quantidade de nodos. Neste sociograma, o tamanho dos objetos, chamados nodos, na análise de redes sociais, diz respeito a sua quantidade de contatos, conhecido como grau de centralidade (centrality degree) o tamanho do nome dos nodos também se refere ao numero absoluto de conexões dos nodos (degree). Ou seja, quanto maior o nodo e quanto maior o seu nome, maior sua quantidade de contatos na rede.

Sociograma 2 - Grau de centralidade da rede sócio-institucional da Caprinovinocultura




O primeiro fato que chama atenção no sociograma é que apenas um nodo não está interligado a rede; o sindicado de trabalhadores rurais em Tuparetama que não citou nenhum contato, e tampouco foi citado. Todos os outros nodos estão de alguma forma conectados. Quando há uma interconexão do tipo observado na imagem, a densidade da rede tende a ser elevada e as possibilidades de contato entre as entidades é bastante alta. Outra observação inicial é o destaque do SEBRAE na rede, cujo número de conexões é bem maior que o da maioria dos outros nodos. O SEBRAE por meio de sua malha de contato, possibilita ligações entre produtores, artesãos, comerciantes, empresas, e entidades governamentais. Quando comparada a centralidade do SEBRAE com a da segunda entidade mais central verifica-se que o primeiro tem quase o dobro de conexões do segundo. Esta unidade do SEBRAE está localizada na cidade de Serra Talhada, o sistema S, tem ainda outro representante bem posicionado, o SEBRAE da cidade de Petrolina. Vale ressaltar que nesta cidade foram visitadas apenas três entidades, já que este município não fazia parte das cidades iniciais, as entidades foram visitadas por terem sido citadas durante o desenrolar do método aplicado à amostra inicial. Grande parte dos nodos de Petrolina está em torno do SEBRAE local, e mesmo com poucos representantes, a rede local de Petrolina é bastante expressiva.

$\mathrm{Na}$ tabela a seguir aparecem em destaque os maiores valores do grau de centralidade.

Tabela 1 - Grau de Centralidade - seleção dos cinco maiores valores

\begin{tabular}{|c|c|}
\hline Entidade & Centralidade \\
\hline SEBRAE & 63.000 \\
\hline STR Afogados da Ingazeira & 33.000 \\
\hline ACCOSE Assoc. Criadores em Sertânia & 28.000 \\
\hline SEBRAE Petrolina & 28.000 \\
\hline CECOR - Centro de Educação Comunitária Rural & 25.000 \\
\hline
\end{tabular}

A observação atenta do Sociograma permite relativizar a importância da quantidade de citações de alguns desses nodos mais bem posicionados. Levando em consideração a posição do nodo, observa-se que entidades como o Sindicato dos trabalhadores Rurais de Afogados da Ingazeira mesmo tento muitas conexões, seus contatos são periféricos, o que tem implicação direta na conectividade do nodo com o centro da rede. Sendo mais específico, grande parte dos contatos do Sindicato de Afogados da Ingazeira são associações rurais de criadores, que obviamente tem sua importância no arranjo, mas não são os pontos de onde as políticas do arranjo emanam. Não apenas o sindicato de Afogados da Ingazeira, mas praticamente todos os outros sindicatos deste tipo, nas demais cidades, funcionam como contato 
das 'bordas da rede', com o centro. É por meio dos Sindicatos que as instituições de orientam as políticas no setor, chegam ao criador. Em algumas cidades, vale acrescentar, as associações de criadores também tem essa função, em outras, tais entidades não estão ligadas aos pequenos criadores.

Entidades como ACCOSE e CECOR se posicionam centralmente na rede e funcionam como stakeholders. A ACCOSE, a Associação de Criadores de Caprinovinos de Sertânia, se destaca por coordenar programas regionais. Tal posição institucional a põe em contato com várias associações de criadores em muitas cidades em Pernambuco e até fora do Estado, com contatos no Estado vizinho, Paraíba. O CECOR tem papel regional também destacado na prestação de apoio aos criadores e produtores e como campo de trabalho para os egressos dos cursos de formação de técnicos da área.

Sociograma 3 - Grau de intermediação da rede sócio-institucional da Caprinovinocultura

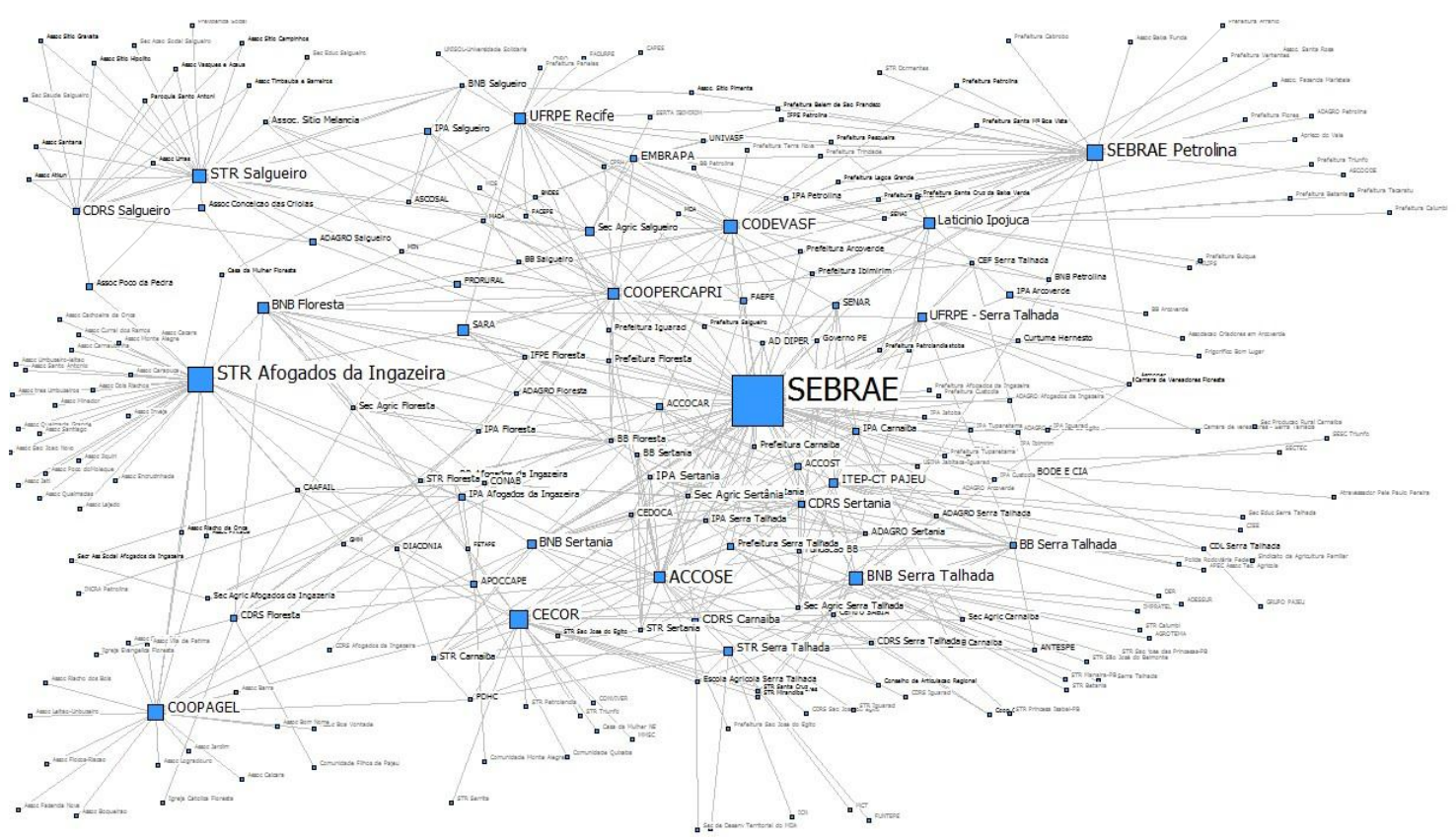

Grau de intermediação (betweenness centrality) refere-se a quantidade de vezes que determinada organização é utilizada por outra como caminho para alcançar uma terceira. O tamanho dos nodos corresponde ao grau. Por meio dessa medida se indica controle de fluxo de informação e capacidade de funcionar como ponte entre nodos não diretamente conectados. O SEBRAE mais uma vez se destaca, pois grande parte dos nodos centrais das cidades visitadas o citou como parceiro, neste sentido, esta entidade funciona como elemento de ligação entre todos os centros da caprinovinocultura do Estado. As demais entidades que tem degree elevado são aquelas que fazem contato entre a periferia e centro da rede, como o SEBRAE 
Petrolina, a ACCOSE, os sindicatos rurais, particularmente o de Afogados da Ingazeira e o de Salgueiro, e entidades como CECOR e COOPAGEL.

O sociograma abaixo mostra a rede dos nodos que, se removidos, desconectam a rede, são os chamados pontos de corte da rede. Na representação o tamanho dos nodos corresponde ao potencial de 'desconectividade', ou seja, quanto maior a representação gráfica do nodo maior sua importância para a manutenção da rede.

Sociograma 4 - Pontos de corte da rede sócio-institucional da Caprinovinocultura

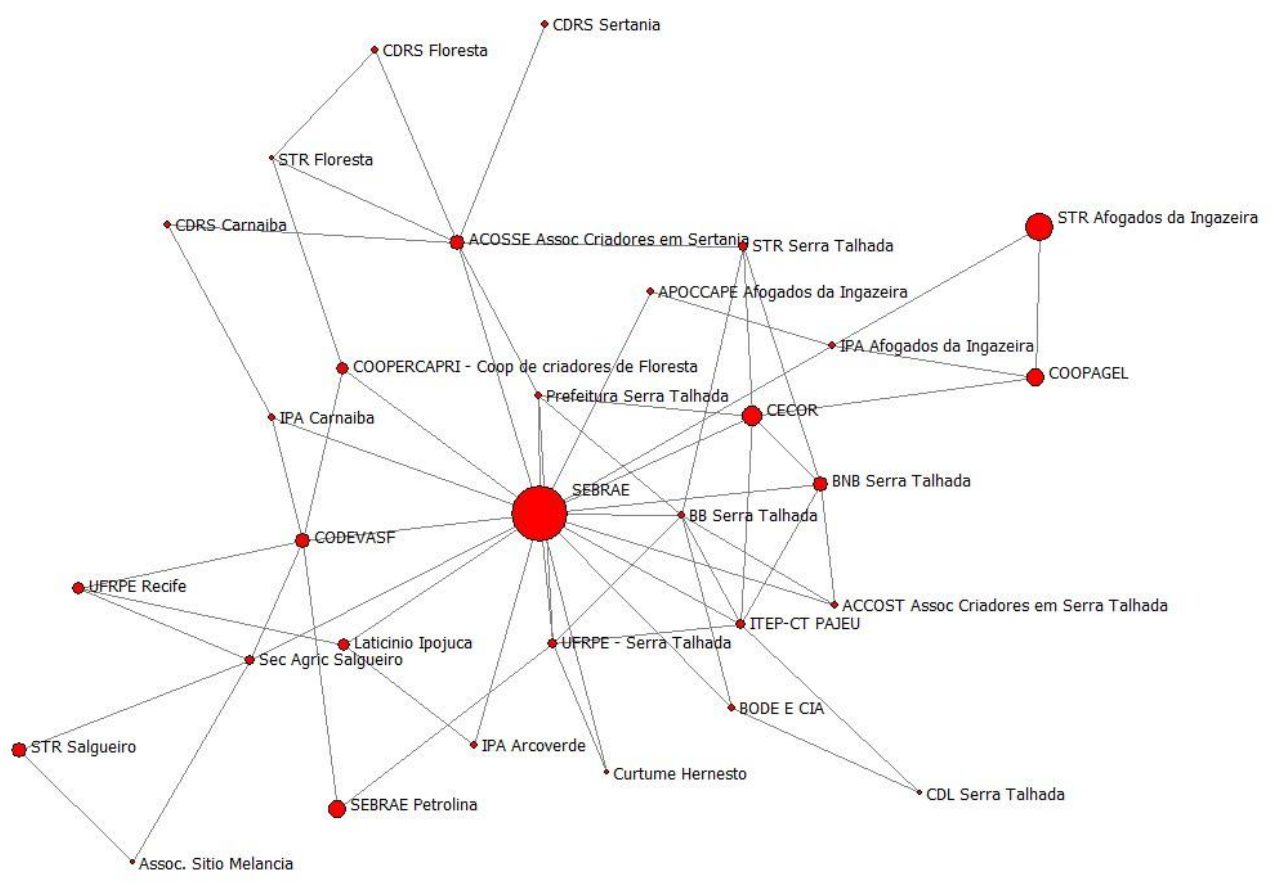

Esses nodos são, em sua maioria, a porta de entrada e de saída de suas redes locais. De um total de trinta e um nodos, treze deles são da cidade de Serra Talhada, dois de Sertânia, e quatro da cidade de Afogados da Ingazeira. Cinco das entidades estão ligadas a esfera de governo estadual ou municipal; cinco é também o numero de associações de criadores ou de produtores representados, e quatro são sindicatos rurais. Como se viu nas redes locais, aparentemente são estes, de fato, os nodos fundamentais para a manutenção da rede: os sindicatos e associações de criadores e as entidades governamentais.

\section{Bases institucionais do APL em rede}

Nesta rede em análise, determinadas entidades locais, levam a crer os dados, impactam na forma com as próximas a ela se relacionam. A rede observada tem um tamanho considerável, em estruturas desta proporção, uma densidade baixa é 
mais comum já que quando se aumenta o número de entidades há uma tendência de queda de densidade das relações. Outra característica que favorece baixas densidades diz respeito a grande quantidade de cidades citadas, embora haja uma concentração em 10 municípios, mais de trinta cidades foram citadas. Tal quantidade, indicador de grande alcance territorial, deveria, em tese, ter como consequência uma baixa densidade entre os nodos. Entretanto a estruturação surpreende pela densidade e coesão. A distância entre os nodos é em média de 3.451 passos - cada nodo passa em média por três nodos e meio para contatar outro - fato que chama atenção, quando se tem em conta que as distâncias entre as cidades é em alguns casos de centenas de quilômetros. A coesão da rede é de 0.3198 um valor alto para o tamanho da rede, e bom indicador da densidade presente. Uma comparação talvez possa ilustra a coesão da rede da caprinovinocultura: estudo realizado pelo ITEP em 2009, sobre a rede dos Centros Vocacionais tecnológicos encontrou coesão de 0.057 entre as entidades componentes.

Um APL deve em tese, fortalecer as empresas pela articulação. Tal envolvimento permitiria maior capacidade de negociação com outras esferas, como governos e entidades representativas, outro fator que deve ser fortalecido é a cooperação e a aprendizagem baseada na troca de informação. Neste sentido, Arranjo Produtivo Local refere-se a um aglomerado de empresas dispostas num mesmo território, caracterizados por especialização produtiva e pelo vínculo interativo de articulação e cooperação entre empresas bem como com atores governamentais, instituições financeiras, associações empresarias e entidades de ensino e pesquisa. A expressão território, no sentido empregado, refere-se a proximidade geográfica, o que se propõe neste trabalho é que o território, em rede, seja compreendido como espaço de reconhecimento, pertencimento e proximidade de relacionamento.

Por este argumento, parece que a palavra chave num APL é relação; é por meio dela que se formam redes nas quais circulam diversos tipos de recurso, seja financeiro, seja na forma de conhecimento, informação etc. A rede aqui apresentada é formada por laços informais entre as entidades, o que implica dizer que elas estão em contato por perceberem a importância da parceria e não por formalização.

No núcleo de um APL tradicional estão - ou deveriam estar - as empresas especializadas, numa segunda linha estariam às empresas fornecedoras de

\footnotetext{
${ }^{8} \mathrm{O}$ indicador varia de ' 0 ' a ' 1 ', quanto mais próximo do 1 , mais coesa é a rede.
} 
componentes necessários as empresas centrais, e por fim, na terceira camada, as 'entidades de apoio': elas dão suporte de infraestrutura de comunicação, de financiamento, transporte, educação e pesquisa, enfim, são os entes governamentais, as universidades e o setor de serviços, seja público ou privado. A capacidade de bom funcionamento de um arranjo depende aparentemente da capacidade de gestão das relações de poder, que nem sempre são simétricas.

Para que as empresas tenha sucesso num $A P L$, um dos pré-requisitos é que elas tenham boas relações verticais e horizontais (Portes, 1990). As relações verticais dizem respeito aos fornecedores e clientes; as relações horizontais, por seu turno, referem-se aos laços que as entidades mantém entre si e que geram outputs positivos para todos os envolvidos na relação. No caso da caprinovinocultura, a reunião - e união - dos criadores, em torno das associações e sindicatos parecem estar na base da eficiência de determinados arranjos locais. Essa colaboração horizontal permite acesso diferenciado ao mercado, geralmente aumenta a eficiência nas rotinas de trabalho e permite o espraiamento de inovação de forma mais acelerada, pois as experiências são compartilhadas.

Basicamente, para que uma rede tenha uma boa distribuição de poder, ela deve ter a centralidade de grau (que indica influência), de intermediação (utilizado como indicador de cooperação), conforme analisamos na seção anterior. Os dados até agora observados, parecem demonstrar que a rede que se está trabalhando é dependente de determinados tipos de atores. Há um padrão de arranjo que se repete nas diversas cidades.

Sociograma 5 - Rede sócio-institucional da Caprinovinocultura por tipo de instituição

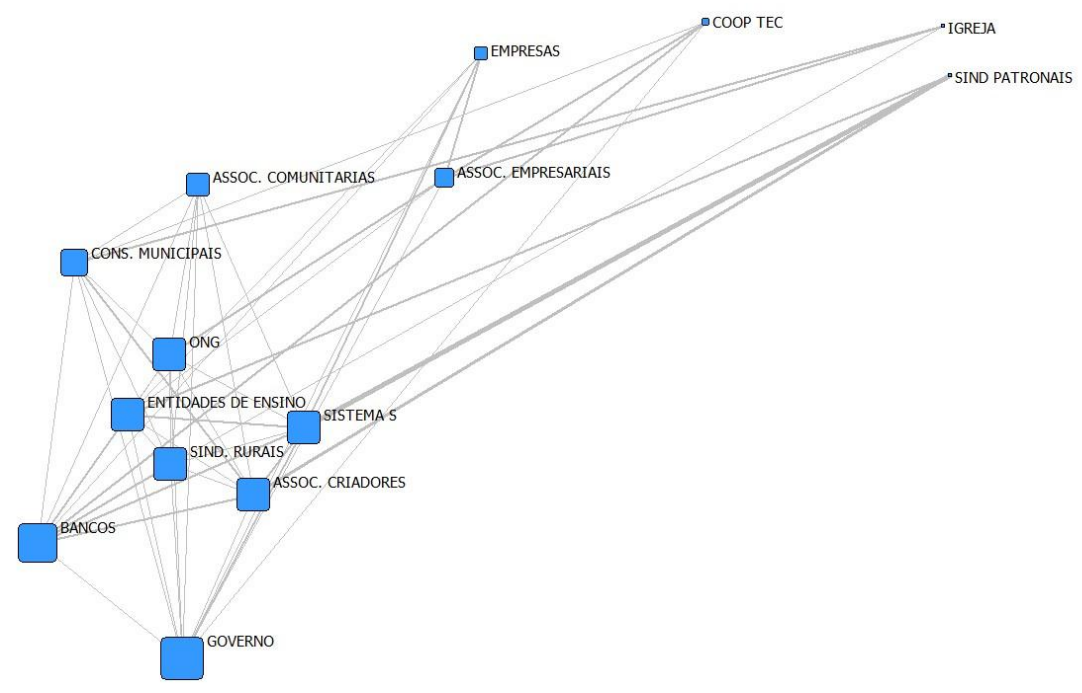


Para tornar a análise gráfica mais clara, optou-se por categorizar as entidades por tipo e atribuir a elas representações gráficas com base no somatório das densidades: quanto maior o nodo, maior a densidade deste tipo de entidade. A leitura do sociograma se faz de baixo para cima e da esquerda para a direita, respectivamente. Assim, o sociograma indica que as entidades governamentais são as que têm mais densidade na rede. Em seguida aparecem as entidades financeiras. Apenas no terceiro nível de densidade aparecem as associações de criadores, sindicatos, sistema S, entidades de ensino e ONGs. Os dados levantados levam a crer que é possível propor uma tipologia de interorganização para o caso da caprinovinocultura a maneira da realizada por Etzkowitz (2009) para o caso da inovação em economias baseadas em conhecimento. A teoria da tríplice hélice parte do princípio de que "a interação entre universidade, indústria e governo é a chave para a inovação e o crescimento em uma economia baseada no conhecimento" (Etzkowitz, 2009, pag.01).

O funcionamento do arranjo da caprinovinocultura, como se pode apreender pelo sociograma por seu turno, depende fortemente de indução governamental. Estas entidades estão no começo e no fim da cadeia produtiva. São delas que advém considerável parte do acompanhamento técnico prestado aos criadores e produtores, no caso em análise, do IPA e das Secretarias de Agricultura; e é também do Estado que se espera garantia de compra por meio de programas como o Fome Zero e Programa de Aquisição de Alimentos.

Um dos fatores que contribui para que as instituições financeiras tenham tão destacada densidade, é que essas entidades aparecem em boa parte das relações recíprocas. Os programas desenvolvidos pelos bancos para estimular a atividade econômica nas cidades parecem ter implicações positiva, provavelmente é por conta desses programas que tais organizações são quase sempre lembradas como elementos ligados a segurança da rede para seus parceiros. Embora não seja possível realizar uma comparação em termos de tempo, já que não se estudou a organização da caprinovinocultura antes e depois desses programas, as cidades que possuem programas específicos como o DRS do Banco do Brasil e os do Banco do Nordeste, têm arranjos locais melhor articulados que as cidades que não possuem programas desse tipo. Nestas formas de financiamento, os bancos fornecem crédito, mas também acompanham a utilização dos recursos e ainda participam dos Conselhos de Desenvolvimento Sustentável, ou seja, participam não só economicamente do arranjo, mas também politicamente. A relação, nestes casos, deixa de ser apenas empresa de crédito e cliente, para agregar sindicados, associações de criadores ou produtores, entidades de ensino etc. 


\section{Considerações finais}

De acordo com os resultados supracitados, dois dos elos dinâmicos dessa rede socioinstitucional do APL de caprinovinocultura de Estado de Pernambuco são o SEBRAE e a as ONGs. Ainda que estas tenham área de atuação menor, é geralmente desse tipo de organização que parte a inovação para o segmento econômico, como também, as novas práticas de manejo para produção. A análise por Regiões das cidades indicou a proximidade entre associações de criadores ou produtores, sindicatos rurais, entidades governamentais e bancos locais como ingrediente de redes coesas e com bom grau de reciprocidade. A análise das centralidades leva a crer que entidades do tipo ONGs, que realizam, entre outras ações, capacitações, são importantes para a base da rede social e estão em contato com os nodos centrais. Observou-se também que as entidades do Sistema $\mathrm{S}$ (SEBRAE, SENAI, SEST, etc.) são fundamentais na rede, estas operam, entre outras atividades, as ações de transferência de tecnologia e apoio organizacional.

No que tange as universidades, estas, principalmente na região em análise, ainda se caracteriza por um papel tímido no empreendedorismo e na indução de inovação e difusão de conhecimento. As escolas técnicas, pelo que foi diagnosticado na pesquisa de campo, tem maior integração com as associações locais, daí o motivo de possuir maior capilaridade que as universidades.

As empresas do setor, além de poucas, não tem densidade expressiva, tampouco centralidades importantes, são empreitadas individuais de risco considerável, num mercado ainda incipiente e pouco organizado. Esse indicador é muito importante para o desenvolvimento do APL, já que as empresas são entidades de suma importância para o desenvolvimento desse tipo de aglomerado.

A análise da densidade da rede permitiu verificar que as entidades governamentais são extremamente importantes para o Arranjo produtivo. São essas entidades que, ao lado das entidades financeiras, operam financeiramente a estruturação e garantem o seu funcionamento. Mesmo sendo em uma economia secundária, ou seja, não atuando de forma hegemônica na economia local-regional, a caprinovinocultura representa uma atividade com bom potencial de agregar varias entidades e criadores, podendo ser, mais que uma forma de subsistencia, uma fonte de desenvolvimento local e regional sustentável no Estado de Pernambuco. 


\section{Referências}

Degenne, A.; Forse, M. (1999). "Introducing social network". London: SAGE Publications.

Etzkowitz, Henry. (2009). "Hélice Tríplice: universidade, indústria e governo: inovação em movimiento". Porto Alegre: EDIPUCRS.

Scott, John. (2000). "Social Network Analysis: a Handbook". 2nd edition. Newbury Park, CA: SAGE Publications.

Hanneman, Robert A. and Mark RIDDLE.(2005). "Introduction to social network methods". Riverside, CA: University of California, Riverside ( published in digital form at http://faculty.ucr.edu/ hanneman/ ).

Mccarty, Christopher. (2002). "Measuring Structure in Personal Networks". Journal of Social Structure 3:1.

Porter, Michael E. (1990). "A Vantagem Competitiva das nações". Rio Janeiro: Campus.

Simmel, Georg. (2005). "Questões fundamentais da sociología". Rio de Janeiro: Jorge Zahar.

Wellman, Barry. (1988). "Structural analysis: from metaphor to substance". In: Wellman, B.; Berkowitz S.D. (Org.). Social Structures: a network approach. Cambridge-New York: Cambridge University Press. 